\title{
Incidence of and Risk Factors for Small Size Babies in Bangladesh
}

\section{Mazharul Islam ${ }^{1}$ and Md Hasinur Rahaman Khan ${ }^{2}$}

${ }^{1}$ Department of Mathematics and Statistics, Sultan Qaboos University, Sultanate of Oman ${ }^{2}$ Applied Statistics, Institute of Statistical Research and Training, University of Dhaka, Dhaka, Bangladesh

\begin{abstract}
Background: Although birth weight is a key predictor of health and survival of a baby, most developing countries often lack this information for various reasons. Under such circumstances, mother's perceived knowledge about the size of her baby has been advocated as an alternative indicator for birth weight. Objective: The aim of this paper is to estimate the incidence of small size babies as perceived by mothers and identify its risk factors.

Methods: The data for the study come from the 2011 Bangladesh Demographic and Health Survey. Descriptive statistical methods, statistical test and multilevel logistic regression model were used for data analysis.

Results: Out of 8,588 children born within five years of the survey, 1,485 (17.2\%) were reported as small in size at birth in Bangladesh. The mean age of mothers at birth of their children was 25.6 years ( $\mathrm{min} 14$ and max 48). Most of the mothers (74\%) received either no antenatal care (ANC) visits (33\%) or small (or inadequate) number (less than 4) of ANC visits (41\%). No ANC or inadequate ANC appeared as a significant predictor of small size babies. Mother's education, parity, pregnancy planning, and region of residence are the other significant determinants of having small size babies. Female babies have 1.3 times more risk to be smaller in size than male babies.

Conclusion: The findings emphasize on the need for targeted intervention for those groups of mothers who were identified with higher risk of having small size baby. More intensive antenatal care visits, counselling and support could help reduce the risk of having small size baby.
\end{abstract}

\section{Introduction}

Weight at birth of a new born baby has long been identified as an important health indicator of health and intellectual growth of the baby [1-2]. Birth weight less than $2.5 \mathrm{~kg}$ is defined as low birth weight (LBW) was estimated to have at least 20 times higher risk of dying in neonatal period than the infants born with normal birth weight (i.e., BW $\geq 2.5 \mathrm{~kg}$ ).3-5 But, those who survive are more likely to have increased risk of disease, undernourishment and development problem. Many studies indicated that LBW children had higher risk of many chronic conditions and functional limitations than the normal birth weight children; had higher rates of cerebral palsy; had lower IQ and more school difficulties; had significantly lower rates of high-school completion [6-10].

Since LBW is mostly preventable, it is considered as an essential public health indicator for monitoring child health goals set by the "World Summit for Children" and "Millennium Development Goal" (MDG) for reducing child mortality [11] Thus an accurate knowledge of weight at birth of a new born helps in monitoring health and development of new born babies. However, despite the importance of LBW as a public health indicator, studies on LBW in developing countries have been very limited due to scarcity of data on LBW, because most of the births in developing countries are occurring outside health facilities; mostly at home, and thus the weight at birth of the babies remain unrecorded. Due to lack of reliable data on birth weight in developing countries, screening for LBW babies and formulation of appropriate interventions programme for them remain as a big challenge for health care providers and, thus, necessitate an alternative measures that can easily be obtained to use as a proxy for LBW. Baby's physical size at birth could be one of such alternative measure.
Recently, researchers are increasingly advocating that data on maternal recalled physical size of the babies that are available from national level population and health surveys in developing countries, like Demographic and Health Surveys (DHSs) and Multiple Indicator Cluster Surveys (MICSs), can be used as an alternative indicator of birth weight when it is lacking. Mothers in general may have difficulties in recalling actual birth weight or may be completely unaware of it, but they can easily recall the physical size of their babies. Thus the national level surveys like DHS and MICS in developing countries asked the mothers whether their newborn babies were "very small, smaller than average, average, larger than average, and very large". Studies have shown that the babies classified by their mothers as smaller than average or very small usually includes babies with LBW, indicating that there is generally a good agreement between LBW and small size of babies at birth [12-15].

Bangladesh is a South Asian developing country having one of the highest incidences of LBW in the world and very high rate of neonatal mortality (32 per 1000 live births). According to the 2003-2004 National Low Birth Weight Survey in Bangladesh, the incidence of LBW was 36\% [16]. Most of the deliveries (71\%) in Bangladesh are taking place at home and they are mostly $(68 \%)$ assisted by traditional 'birth attendants', relatives or friends [17]. Under these circumstances babies weight are not maintained due to lack of weighing facilities as *Corresponding Author: Dr. M. Mazharul Islam, Department of Mathematics and Statistics, College of science, Sultan Qaboos University P.O. Box 36, PC 123, Muscat Sultanate of Oman; E-mail: mislam@squ.edu.om

Citation: Islam MM, Khan MHR (2016) Incidence of and Risk Factors for Smal Size Babies in Bangladesh. Int J Community Fam Med 1: 123. doi: https://doi. org/10.15344/2456-3498/2016/123

Copyright: (@) 2016 Islam et al. This is an open-access article distributed under the terms of the Creative Commons Attribution License, which permits unrestricted use, distribution, and reproduction in any medium, provided the original author and source are credited. 
well as lack of knowledge about importance of birth weight of babies. Thus, mother's perceived size at birth of their newborn babies that are available from nationally representative survey like DHS could be a viable option for using as an alternative indicator of birth weight in Bangladesh. With this backdrop, this study aimed to estimate the incidence of small size babies on the basis of mothers' reporting and identify the risk factors of small size at birth or by implication LBW. We used mother's recall of size at birth as the proxy to birth weight and mother's recall of very small or smaller than average size at birth as the proxy to LBW. The findings of the study is expected to help monitor the health and survival of new born and design policy and programs targeting to reduce the risk of LBW in Bangladesh.

\section{Materials and Methods}

This study utilized data from the 2011 Bangladesh Demographic and Health Survey (BDHS). The survey covered 17,842 married girls and women of age 10-49 years from 17,141 randomly selected households covering 600 enumeration areas (clusters) throughout Bangladesh; 207 in urban areas and 393 in rural areas. The 2011 BDHS is the sixth in a series of national-level population and health surveys conducted as part of the global Demographic and Health Surveys (DHS) program with financial support provided by the United States Agency for International Development (USAID). The survey utilized a two-stage stratified cluster sample of households based on the 2011 Bangladesh Population and Housing Census to produce separate estimates for key indicators for each of the seven divisions of the country-Barisal, Chittagong, Dhaka, Khulna, Rajshahi, Rongpur, and Sylhet. The further detailed of the survey may be seen in NIPORT et al. [17].

Our analysis considered mother's recall of size at birth of their babies born within five years of the survey date as outcome or dependent variable and maternal, child, and socio-economic and demographic factors as explanatory variables. In the 2011 BDHS, data on infant's size at birth were obtained by asking mothers: When (NAME) was born, was he/she very large, larger than average, average, smaller than average, or very small? We created a binary outcome variable: "small size" and " $\geq$ average size". Small size consists of "very small and smaller than average size', while " $\geq$ average size" consists of 'very large, larger than average and average size' babies. Maternal factors included mother's age, education, employment, number of antenatal care (ANC) visit, height, BMI, wantedness of pregnancy, pregnancy complications and use of iron tablets during pregnancy. In Bangladesh, ANC is provided mainly by medically trained providers that include: doctors, nurse, midwife, paramedics and family welfare visitors (FWV). Some traditional birth attendant and NGO workers also provide ANC services. However, those mothers who received ANC visits, they mostly received it from medically trained providers. For example, out of $68 \%$ mothers who received at least one ANC visit, $55 \%$ received it from medically trained providers [17]. Following the guidelines of World Health Organization[18], the Ministry of Health and Family Welfare (MoHFW) of Bangladesh also recommend for at least four ANC visits by every pregnant women under normal circumstances [19]. Child related factors included child's gender, birth order, and birth interval. The socio-demographic factors included household's wealth index, father's occupation and education, place of residence and region of residence. The wealth index - a composite index of the economic condition of a household - was created using the principal components and factor analysis of household asset variables such as possession of TV, refrigerator, car, household construction materials etc [20]. The 2011 BDHS gathered complete information on maternal recalled size at birth of 8,588 children born within five years of the survey. There were some missing values for some explanatory variables, and the analysis was done considering only the valid cases for those variables.

We estimated the incidence of small size babies as proxy indicator of LBW and the characteristics of infants across a number of socioeconomic and demographic factors using descriptive statistics. To analyze the association between mother's recall of small size at birth and the explanatory variables we used cross tabulation and Chi-square test $\left(\chi^{2}\right)$. A p-value $<0.05$ is considered as statistically significant. The significant factors identified in the bivariate analysis were further examined using multiple logistic regressions. Logistic regression model was fitted considering maternal reported size at birth of infants as a dichotomous dependent variable, with small size coding as ' 1 ' and ' 0 ' otherwise, and maternal, child and socio-demographic factors as predictor variables. The resulting adjusted or net effect of a predictor was measured by the odds ratio with controlling the effect of all other predictors.

This study utilized data from the 2011 BDHS requiring no direct data collection from human subjects, and, therefore, no ethical approval was needed. The data were completely anonymous. However, request to access datasets from measure DHS website is made and the websites has allowed the same before analyses is made.

\section{Results}

Table 1 presents the distribution of infants by their size at birth as perceived by their mothers. The data indicate that $5 \%$ of children were perceived as very small in size by the mothers, $12 \%$ as smaller than average in size, and $83 \%$ as $\geq$ average in size. Overall, $17.2 \%$ (95\% CI: $15.2 \%-19.2 \%$ ) of the children were perceived to be small in size by their mothers, who constituted our study subjects.

\begin{tabular}{|l|l|l|}
\hline Recalled size at birth & Number & Percentage \\
\hline Very large & 173 & 2.0 \\
\hline Larger than average & 1,100 & 12.9 \\
\hline Average & 5,830 & 67.9 \\
\hline Smaller than average & 1,043 & 12.1 \\
\hline Very small & 442 & 5.1 \\
\hline Total & 8,588 & 100.0 \\
\hline
\end{tabular}

Table 1: Percentage distribution of all live births by maternal recalled size at birth, BDHS 2011

Table 2 shows the distribution of children by their characteristics. The mean age of mothers at birth of their children was 25.6 years ( $\mathrm{min}$ 14 and max 48). Most of the children (64\%) had mothers of age 20-29 years, $14 \%$ with mothers age less than 20 years and $9 \%$ with mothers age of 35 years. About $31 \%$ of the children had mothers with primary education, $42 \%$ had secondary education and a small proportion (8\%) had higher than secondary education. Only $10 \%$ mothers were working in paid employment. About $36 \%$ of the children were first order birth. Half (51\%) of the children were male. One-fourth $(27 \%)$ of the children were either products of unintended (wanted later) or unwanted (wanted no more) pregnancy. Mothers of one-third (33\%) of the children never received antenatal care (ANC) visits and onefourth (26\%) received 4 or more ANC visits. More than half (59\%) of the children had mothers with normal BMI (18.5-24.9) and height $145 \mathrm{~cm}$ or more (87\%). One-third (33\%) of mothers had pregnancy complications and almost all (98\%) received iron supplementation. Most of the children (70\%) occurred from rural areas with fathers having no education or primary education (59\%). 
Citation: Islam MM, Khan MHR (2016) Incidence of and Risk Factors for Small Size Babies in Bangladesh. Int J Community Fam Med 1: 123. doi: https://doi. org/10.15344/2456-3498/2016/123

Page 3 of 7

\begin{tabular}{|c|c|c|c|c|c|}
\hline \multirow[t]{2}{*}{ Factors } & \multicolumn{2}{|l|}{ Total Births } & \multicolumn{2}{|c|}{ Perceived Size at Birth } & \multirow[t]{2}{*}{$P$-value } \\
\hline & $\mathbf{N}$ & $\%$ & Small & $\geq$ Average & \\
\hline Total & 8588 & 100 & 17.2 & 82.7 & \\
\hline Mother's age at birth of child & & & & & 0.005 \\
\hline$<20$ & 1161 & 13.5 & 20.6 & 79.4 & \\
\hline $20-29$ & 5453 & 63.5 & 16.4 & 83.6 & \\
\hline $30-34$ & 1230 & 14.3 & 17.4 & 82.6 & \\
\hline $35+$ & 744 & 8.7 & 17.5 & 82.5 & \\
\hline Mean age $( \pm S D)$ & $25.6( \pm 5.9)$ & & & & \\
\hline Mothers education & & & & & 0.000 \\
\hline No education & 1655 & 19.3 & 20.1 & 79.9 & \\
\hline Primary & 2634 & 30.7 & 18.1 & 81.9 & \\
\hline Secondary & 3633 & 42.3 & 16.6 & 83.4 & \\
\hline Higher & 666 & 7.8 & 11.0 & 89.0 & \\
\hline Employment status & & & & & 0.140 \\
\hline Not employed/house wife & 7739 & 90.1 & 17.4 & 82.6 & \\
\hline Employed & 849 & 9.9 & 15.9 & 84.1 & \\
\hline Birth order & & & & & 0.010 \\
\hline 1 & 3095 & 36.1 & 18.2 & 81.8 & \\
\hline $2-3$ & 3943 & 45.9 & 16.0 & 84.0 & \\
\hline $4+$ & 1550 & 18.0 & 18.8 & 81.2 & \\
\hline Children gender & & & & & 0.000 \\
\hline Male & 4418 & 51.4 & 15.7 & 84.3 & \\
\hline Female & 4170 & 48.6 & 18.9 & 81.1 & \\
\hline Pregnancy was wanted & & & & & 0.090 \\
\hline Then & 6281 & 73.1 & 16.7 & 83.3 & \\
\hline Later & 1257 & 14.6 & 18.4 & 81.6 & \\
\hline No more & 1049 & 12.2 & 19.5 & 80.5 & \\
\hline Number of ANC visit & & & & & 0.000 \\
\hline 0 & 2422 & 33.4 & 20.4 & 79.6 & \\
\hline $1-3$ & 2909 & 40.2 & 17.4 & 82.6 & \\
\hline $4+$ & 1914 & 26.4 & 13.2 & 86.8 & \\
\hline Preceding birth interval & & & & & 0.096 \\
\hline$<24$ months & 688 & 12.5 & 18.6 & 81.4 & \\
\hline$\geq 24$ months & 4805 & 87.5 & 16.5 & 83.5 & \\
\hline Mother's height & & & & & 0.008 \\
\hline$<145 \mathrm{~cm}$ & 1099 & 12.8 & 19.9 & 80.1 & \\
\hline$\geq 145 \mathrm{~cm}$ & 7489 & 87.2 & 16.9 & 83.1 & \\
\hline Mother's BMI & & & & & 0.002 \\
\hline$<18.5$ & 2319 & 27.0 & 19.5 & 80.5 & \\
\hline $18.5-24.9$ & 5037 & 58.7 & 16.8 & 83.2 & \\
\hline$\geq 25.0$ & 1232 & 14.3 & 15.3 & 84.7 & \\
\hline Any pregnancy complications & & & & & 0.307 \\
\hline Yes & 1570 & 32.6 & 16.2 & 83.8 & \\
\hline No & 3244 & 67.4 & 17.6 & 84.4 & \\
\hline Took iron during pregnancy & & & & & 0.541 \\
\hline Yes & 194 & 2.4 & 17.0 & 83.0 & \\
\hline No & 7984 & 97.6 & 17.2 & 83.0 & \\
\hline
\end{tabular}


Citation: Islam MM, Khan MHR (2016) Incidence of and Risk Factors for Small Size Babies in Bangladesh. Int J Community Fam Med 1: 123. doi: https://doi. org/10.15344/2456-3498/2016/123

Page 4 of 7

\begin{tabular}{|c|c|c|c|c|c|}
\hline \multirow[t]{2}{*}{ Factors } & \multicolumn{2}{|c|}{ Total Births } & \multicolumn{2}{|c|}{ Perceived Size at Birth } & \multirow[t]{2}{*}{$P$-value } \\
\hline & $\mathbf{N}$ & $\%$ & Small & $\geq$ Average & \\
\hline Father's education & & & & & 0.000 \\
\hline No education & 2423 & 28.2 & 19.2 & 80.8 & \\
\hline Primary & 2520 & 29.4 & 18.0 & 82.0 & \\
\hline Secondary & 2494 & 29.1 & 16.8 & 83.2 & \\
\hline \multicolumn{6}{|l|}{ Higher } \\
\hline 1145 & 13.3 & 12.8 & 87.2 & & \\
\hline Fathers occupation & & & & & 0.192 \\
\hline Professional/technical & 2137 & 24.9 & 15.9 & 84.1 & \\
\hline Business & 1909 & 22.2 & 17.7 & 82.3 & \\
\hline $\begin{array}{l}\text { Factory worker/blue } \\
\text { collar service }\end{array}$ & 1285 & 15.0 & 16.4 & 83.6 & \\
\hline $\begin{array}{l}\text { Labour (skilled/ } \\
\text { unskilled) }\end{array}$ & 692 & 8.1 & 19.4 & 80.6 & \\
\hline $\begin{array}{l}\text { Farmer/agricultural } \\
\text { work }\end{array}$ & 2033 & 23.7 & 17.8 & 82.2 & \\
\hline Others & 532 & 6.2 & 19.2 & 80.8 & \\
\hline Region & & & & & 0.000 \\
\hline Barisal & 957 & 11.1 & 14.3 & 85.7 & \\
\hline Chittagong & 1713 & 19.9 & 20.4 & 79.6 & \\
\hline Dhaka & 1422 & 16.6 & 16.1 & 83.9 & \\
\hline Khulna & 963 & 11.2 & 15.6 & 84.4 & \\
\hline Rajshahi & 1057 & 12.3 & 15.7 & 84.3 & \\
\hline Rangpur & 1091 & 12.7 & 13.7 & 86.3 & \\
\hline Sylhet & 1385 & 16.1 & 21.9 & 78.1 & \\
\hline Place of residence & & & & & 0.032 \\
\hline Urban & 2621 & 30.5 & 16.1 & 83.9 & \\
\hline Rural & 5967 & 69.5 & 17.8 & 82.2 & \\
\hline Wealth index & & & & & 0.001 \\
\hline Poorest & 1908 & 22.2 & 19.8 & 80.2 & \\
\hline Poorer & 1669 & 19.4 & 18.6 & 81.4 & \\
\hline Middle & 1637 & 19.1 & 17.0 & 83.0 & \\
\hline Richer & 1681 & 19.6 & 15.9 & 84.1 & \\
\hline Richest & 1693 & 19.7 & 14.9 & 85.1 & \\
\hline
\end{tabular}

\section{Correlates of small size babies}

Table 2 presents bivaraiate analysis showing unadjusted association between maternal recalled size of babies and socio-economic and demographic factors. The results indicate significant differential effects of maternal age, education, number of ANC visits, height of mothers, BMI of mothers, wantedness of pregnancy, birth order of child, sex of child, father's education, region of residence, place of residence and wealth status on mothers' recall of size at birth of their babies. Bivariate analysis, however, shows unadjusted effects of a factor on maternal perceived size at birth. The unadjusted significant factors with $p$-value $<0.05$ as well as marginally significant factors with p-value $<0.10$ were further analyzed using multilevel multivariate logistic regression to obtain adjusted effect of a factor on size at birth after controlling the effects of other factors (Table 3). According to the results of multivariate analysis, mother's education, number of ANC visits, wantedness of pregnancy, region of residence, birth order of child and sex of child appeared as significant predictors of small size babies.

The educational levels of mother show significant negative association with the incidence of mother's recall of size of babies. The incidence of small size babies and there by LBW decreases as the level of education increases. Babies who have mothers with no education were found to be 1.6 times more likely to be smaller sized $(\mathrm{OR}=1.587$; $95 \% \mathrm{CI}=1.176-2.143$ ) compared to those having mothers with higher level of education. Frequency of ANC visit shows significant positive association with maternal perceived size of babies. Infants born to 
Citation: Islam MM, Khan MHR (2016) Incidence of and Risk Factors for Small Size Babies in Bangladesh. Int J Community Fam Med 1: 123. doi: https://doi. org/10.15344/2456-3498/2016/123

Page 5 of 7

\begin{tabular}{|c|c|c|c|c|c|c|}
\hline \multirow[t]{2}{*}{ Factors } & \multirow[t]{2}{*}{ Estimate } & \multirow[t]{2}{*}{ Stand. Error } & \multirow[t]{2}{*}{ OR } & \multicolumn{2}{|c|}{$95 \% \mathrm{CI}$ of OR } & \multirow[t]{2}{*}{ P-value } \\
\hline & & & & lower & upper & \\
\hline \multicolumn{7}{|l|}{ Region } \\
\hline Barisal & .041 & .150 & 1.041 & 0.776 & 1.398 & .786 \\
\hline Chittagong & .452 & .130 & 1.572 & 1.218 & 2.029 & .000 \\
\hline Dhaka & .115 & .136 & 1.122 & 0.860 & 1.464 & .395 \\
\hline Khulna & .059 & .148 & 1.061 & 0.794 & 1.418 & .689 \\
\hline Rajshahi & .091 & .144 & 1.095 & 0.826 & 1.453 & .528 \\
\hline Rangpur & & & 1.000 & Reference & & \\
\hline Sylhet & .529 & .136 & 1.700 & 1.299 & 2.217 & .000 \\
\hline \multicolumn{7}{|l|}{ Mothers education } \\
\hline No education & .539 & .165 & 1.587 & 1.176 & 2.143 & .001 \\
\hline Primary & .461 & .153 & 1.434 & 1.079 & 1.097 & .002 \\
\hline Secondary & .360 & .145 & 1.715 & 1.241 & 2.372 & .013 \\
\hline Higher & & & 1.000 & Reference & & \\
\hline \multicolumn{7}{|l|}{ Number of ANC visit } \\
\hline 0 & .375 & .096 & 1.455 & 1.205 & 1.759 & .000 \\
\hline $1-3$ & .246 & .089 & 1.279 & 1.074 & 1.522 & .005 \\
\hline $4+$ & & & 1.000 & Reference & & \\
\hline \multicolumn{7}{|l|}{ Pregnancy was wanted } \\
\hline Then & & & 1.000 & Reference & & \\
\hline Later & .187 & .088 & 1.205 & 1.014 & 1.434 & .034 \\
\hline No more & .210 & .104 & 1.235 & 1.007 & 1.514 & .042 \\
\hline \multicolumn{7}{|l|}{ Birth order } \\
\hline 1 & .278 & .111 & 1.321 & 1.062 & 1.643 & .012 \\
\hline $2-3$ & .005 & .099 & 1.005 & .776 & 1.398 & .957 \\
\hline $4+$ & & & 1.000 & Reference & & \\
\hline \multicolumn{7}{|l|}{ Children gender } \\
\hline Male & & & 1.000 & Reference & & \\
\hline Female & .270 & .064 & 1.310 & 1.156 & 1.486 & .000 \\
\hline
\end{tabular}

mothers with no ANC visit $(\mathrm{OR}=1.455 ; 95 \% \mathrm{CI}=1.205-1.759)$ and those with less than 4 ANC visits $(\mathrm{OR}=1.279 ; 95 \% \mathrm{CI}=1.074-1.522)$ were found to have higher risk for smaller size compared to those who received the recommended four or more ANC visits. Female babies were found to have 1.3 times higher risk of being smaller than their male counterparts $(\mathrm{OR}=1.310 ; 95 \% \mathrm{CI}=1.156-1.492)$. The outcome of unintended (want later) $(\mathrm{OR}=1.205 ; 95 \% \mathrm{CI}=1.014-1.434)$ or "unwanted" $(\mathrm{OR}=1.235 ; 95 \% \mathrm{CI}=1.007-1.514)$ pregnancies were respectively at 1.21 and 1.24 times higher risk of being small in size compared to outcomes of wanted pregnancies. Maternal perceived size at birth of babies show significant variation across the seven regions of the country. The incidence of small size of babies were highest in Sylhet region (21.9\%) closely followed by Chittagong region (20.4\%) and lowest in Rangpur region. Babies from Sylhet (OR=1.700; 95\%CI $=1.299-2.217)$ and Chittagong ( $\mathrm{OR}=1.572$; $95 \% \mathrm{CI}=1.218$ 2.029) regions have significantly higher risks of having small size than those from Rangpur and other regions. First born child are 1.32 times more likely to be small in size than their higher order counter parts $(\mathrm{OR}=1.321 ; 95 \%=\mathrm{CI}=1.062-1.643)$.
Although the bivariate analysis in Table 2 showed significant association between maternal perceived small size at birth of babies and age of mothers at birth of babies, mothers' height, mothers' BMI, urban-rural place of residence, wealth status and fathers' education, but these factors showed no significant independent effect on size at birth after controlling the effects of other factors in multivariate analysis. This is possible due to the fact that the effect of these factors may be confounded with the effects of other factors. For example, maternal age is confounded with birth order and wealth status is likely to be confounded with education. Although not statistically significant, maternal age showed a U-shaped relationship with the risk of small size baby.

\section{Discussion}

The results indicate that about $17 \%$ newborn babies in Bangladesh are attributed as small in size at birth by the mothers. The result is comparable with the finding from Nepal and India, the two neighboring countries with similar socio-economic and 
demographic conditions. The proportion of small size babies in Bangladesh as perceived by mothers is found to be slightly higher than in Nepal (16\% in 2011)21, but lower than in India $(20.5 \%$ in 2007) [22].

Our study identified many significant predictors of maternal perceived small size babies in Bangladesh. These are: mother's education, frequency of ANC visit, region of residence, wantedness of pregnancy, birth order and child's gender. Mother's education level shows monotonic negative association with the small size at birth. Maternal education has both independent and mediating effect on birth size. It affects birth size through increasing mother's knowledge about healthy life style and health care processes and greater utilization of health care services by mothers. The higher incidence of small size babies among mothers with no or lower educational level in Bangladesh might be linked with the fact that such mothers are less likely to go for ANC visits or more likely to receive inadequate number of ANC visits. Besides it is more likely that these mothers have low economic condition, living in the rural areas with inadequate health facilities, and poor knowledge about health, hygiene and nutrition.

Our analysis reveals that the frequency of antenatal care (ANC) visits had significant independent effects on having small size babies. The usefulness of timely and adequate number of ANC visits (at least 4 visits) for the reduction of risk of having small size babies and there by LBW and other adverse outcomes of pregnancy is well established [23-25]. Regular attendance to ANC visits is essential for seeking care during pregnancy and childbirth. It helps improve dietary practices and uptake of nutrient supplements of mothers, monitor recommended weight gain during pregnancy, identify medical and obstetric complications, facilitate early interventions and treatment, and improve neonatal outcomes $[24,25]$. The data indicate low level of ANC visit in Bangladesh as one-third mothers never attended to ANC visits (Table 2). Among those who attended ANC visits, the median number of visits appeared to be 3.3 visits which is less than the prescribed at least 4 ANC visits.

The study identified geographical regions as significant predictor of small size babies as perceived by mothers. Infants from Chittagong and Sylhet region had relatively higher risk of being small in size. These are the two eastern divisions of Bangladesh characterized by high fertility and childhood mortality, low level of education, poor access to health care services and utilization, and low social status of women [17]. All these typical factors of the geographical locations might be linked with the poorer outcomes of pregnancy like small size at birth.

This study identifies unintended pregnancy as a significant determinant of small size babies as perceived by mothers. Outcomes of unintended pregnancies had more than $20 \%$ higher risk of being smaller in size. Women who experienced unplanned pregnancies are less likely to receive proper antenatal care than those with planned pregnancies. Unintended pregnancies have a wide range of adverse effects on pregnancy outcomes, mental health, antenatal care, breastfeeding and infant morbidity and mortality [26-29] The high rate of small size baby and there by LBW in Bangladesh could be explain partly by the high rate of unplanned pregnancies. Despite a high rate of contraceptive use in Bangladesh (61\% in 2011), many women (28\%) still experience unintended or unwanted pregnancies in Bangladesh [17,30]

Int J Community Fam Med

ISSN: $2456-3498$
Birth order of infants shows significant independent effect on maternal perceived size at birth. We observe that first time births have 1.3 times higher risk of being small in size than the higher order births. Our findings are in agreement with others studies.31,32 The observed higher risk of small size baby among first time or lower order births may be associated with mothers' young or advanced age, unplanned pregnancies, and pregnancy complications, such as anemia, hypertension or diabetics.

The main strength of this paper is that it has utilized national level data of a population survey that used "validated questionnaires and methodology", ensuring that the finding could be generalizable to the national as well as subnational levels. The study is the first of its kind in Bangladesh, reporting socio-economic and demographic determinants of small size babies or by implication low birth weight babies using maternal perceived birth size of their infants as an alternative measure of birth weight in the absence of nationally representative birth weight data. Nevertheless, it is not free from limitations. The data used in the study is cross sectional in nature and there is possibility that responses on size of baby at birth may be prone to recall biases, particularly our main outcome variable, size at birth as perceived by mothers. Due to non-availability of data on several important variables, such as maternal weight gain during pregnancy, pre- and during pregnancy health status, food consumption, diet and life style of mothers, we could not control their effects. Thus we could not rule out the issue of residual confounders.

\section{Conclusion}

The present study reports a very high rate (17\%) of maternal perceived small size babies (and by implication a LBW rate) in Bangladesh which is a major challenge for further reduction of neonatal morbidity and mortality. The study findings underline the necessity of targeted intervention for the sub-groups of mothers with higher risk of having small size babies. The findings of higher risk of having small size baby among mothers with no ANC visits or less than 4 ANC visits underscore the importance of regular and adequate ANC visits during pregnancy. Regular ANC attendance would help diagnose medical and obstetric complications, and allow for early interventions and treatment, thus reducing the risk of small size baby or LBW baby. The findings of higher prevalence of small size babies as perceived by mothers in Chittagong and Sylhet divisions underscore the requirement to develop policies specific to these regions. It is important to find out why these regions have higher prevalence of small size baby and develop specific solutions for these regions. Mothers with first time pregnancy, low level of education, unplanned pregnancy, Chittagong and Sylhet region and less than 4 ANC visits should be given priority by health care providers with greater psychosocial support. In Bangladesh, birth weight is still not given priority in national health programme. Parents and health providers are still less concern about causes and consequences of LBW. Thus, health education through mass media should focus on the causes and consequences of small size babies in Bangladesh.

\section{Acknowledgements}

The authors would like to thank Measure DHS for granting access to BDHS datasets. The authors are also thankful to the editor and reviewers for their critical and useful comments that helps to improve the quality of the manuscript enormously. The views expressed herein are solely those of the authors and do not necessarily reflect the views of any institution or organization. 
Citation: Islam MM, Khan MHR (2016) Incidence of and Risk Factors for Small Size Babies in Bangladesh. Int J Community Fam Med 1: 123. doi: https://doi. org/10.15344/2456-3498/2016/123

\section{Competing Interests}

The authors have no conflict of interest to declare.

\section{References}

1. WHO and UNICEF (2004) Low Birth weight: Country, Regional and Global Estimates. United Nations Children's Fund (UNICEF), New York, and WHO, Geneva

2. Villar J, Belizan JM (1982) The relative contribution of prematurity and fetal growth retardation to low birth weight in developing countries and developed societies. Am J Obstetr Gynecol 143: 793-798.

3. World Health Organization (WHO) (1992) Low Birth Weight: A tabulation of available information, WHO/MCH/92.2, World Health Organization, Geneva, and UNICEF, New York, USA.

4. McCormick M (1985) The contribution of low birth weight to infant mortality and childhood morbidity. New Engl J Med 312: 82-90.

5. Kramer M (1987) Determinants of low birth weight: methodological assessment and meta-analysis. Bull World Health Organ 65: 663-737.

6. Escobar GJ, Littenberg B, Petitti DB (1991) Outcome among surviving very low birth weight infants: A meta-analysis. Archi Disease Child 66: 204-211.

7. Eriksson JG, Forsen T, Tuomilehto J, Osmond C, Barker DJP (2001) Early growth and coronary heart disease in later life: Longitudinal study. Brit Med J 322: 949-953.

8. Klebanov PK, Brooks-Gunn, J, McCormick MC (1994) School achievement and failure in very low birth weight children. J Dev Behav Pediatr 15: 248256.

9. Islam MM (2015) The Effects of Low Birth Weight on School Performance and Behavioral Outcomes of Elementary School Children in Oman, Oman Med J 30: 241-251.

10. Conley D, Bennet NG (2000) Is biology destiny? Birth weight and life chances. Am Socio Rev 65: 458-467.

11. United Nations (UN) (2001) Road Map Towards the Implementation of the United Nations Millennium Declaration, Report of the Secretary-general A/56/326.

12. Blanc A, Wardlaw $T$ (2005) Monitoring low birth weight: an evaluation of international estimates and an updated estimation procedure. Bull World Health Organ 83: 178-185.

13. Channon AAR (2011) Can mothers Judge the size of their newborn? Assessing the determinants of a mother's perception of a baby's size at birth. J Biosoc Sci 43: 555-573.

14. Boerma JT, Weinstein KI, Rutstein SO, Sommerfelt AE (1996) Data on birth weight in developing countries: Can surveys help? Bull World Health Organ 74: $209-216$

15. Islam MM (2014) Can Maternal Recalled Birth Size be Used as a Proxy Measure of Birth Weight? An Evaluation Based on a Population Health Survey in Oman. Mat Child Health J 18: 1462-1470.

16. Bangladesh Bureau of Statistics (BBS) and UNICEF (2005) National Low Birth Weight Survey of Bangladesh, 2003-2004. Planning Division, Ministry of Planning, Government of People's Republic of Bangladesh, Dhaka.

17. National Institute of Population Research and Training (NIPORT), Mitra and Associates, and ICF International (2013) Bangladesh Demographic and Health Survey 2011. Dhaka, Bangladesh and Calverton, Maryland, USA NIPORT, Mitra and Associates, and ICF International.

18. World Health Organization (WHO) (2007) Standards for Maternal and Neonatal Care. Geneva, Switzerland.

19. Ministry of Health and Family Welfare (MOHFW) [Bangladesh] (2011) Health, Population and Nutrition Sector Development Program (HPNSDP), (July 2011-June 2016). Volume I, Program Implementation Plan (PIP). Dhaka, Bangladesh: MOHFW, Government of the People's Republic of Bangladesh.

20. Filmer D, Pritchett LH (2001) Estimating wealth effects without expenditure data--or tears: an application to educational enrollments in states of India. Demography 38: 115-32.
21. Khanal V, Sauer K, Karkee R, Zhao Y (2014) Factors associated with small size at birth in Nepal: further analysis of Nepal Demographic and Health Survey 2011. BMC Pregn Childb 14: 14-32.

22. Sreeramareddy CT, Ramakrishnareddy N, Kumar H, Sathian B, Arokiasamy $\mathrm{J}$ (2011) Prevalence, distribution and correlates of tobacco smoking and chewing in Nepal: a secondary data analysis of Nepal demographic and health survey-2006. Substance Abuse Treat Prev Policy 6: 33.

23. Bloom S, Lippeveld T, Wypij D (1999) Does antenatal care make a difference to safe delivery? A study in urban Uttar Pradesh, India. Health Policy Plan14: 38-48.

24. Hueston WJ, Gilbert GE, Davis L, Sturgill V (2003) Delayed prenatal care and the risk of low birth weight delivery. J Com Health 28: 199-208.

25. White DE, Fraser-Lee NJ, Tough S, Newburn-Cook CV (2006) The content of prenatal care and its relationship to preterm birth in Alberta, Canada. Health Care for Women Int 27: 777-792.

26. Shah PS, Balkhair T, Ohlsson A, Beyene J, Scott F, et al. (2011) Intention to become pregnant and low birth weight and preterm birth: a systematic review. Matern Child Health J 15: 205-16.

27. Bitto A, Gray RH, Simpson JL, Queenan JT, Kambic RT, et al. (1997) Adverse outcomes of planned and unplanned pregnancies among users of natural family planning: a prospective study. Am J Pub Health 97: 338-343.

28. Eggleston E, Tsui AO, Kotelchuck M (2001) Unwanted pregnancy and Low birth weight in Ecuador. Am J Public Health 91: 808-810.

29. Mohllajee AP, Curtis KM, Morrow B, Marchbanks PA (2007) Pregnancy intention and its relationship to birth and maternal outcomes. Obstet Gynecol 109: 678-686.

30. Eggleston E (1998) Unintended pregnancy and use of prenatal care in Ecuador, paper presented at the annual meeting of the American Public Health Association, Washington DC.

31. Mondal B (2000) Risk factor for low birth weight in Nepali Infants. Indian J Pediatr 67: 477-482.

32. Islam MM (2013) Incidence of and Risk Factors for Low Birth Weight in Oman: A Population Based Study. Int J Matern Child Health 1: 77-86.

This article was originally published in a special issue:

\section{Infant Care and Childbirth Intervention}

Handled by Editor(s):

Prof. Khalid Umran Al-Umran

Department of Pediatrics

University of Dammam

Saudi Arabia 